\title{
BMJ Furthering the understanding of Open olfaction, prevalence of loss of smell and risk factors: a population-based survey (OLFACAT study)
}

\author{
Joaquim Mullol, ${ }^{1,2,7}$ Isam Alobid, ${ }^{1,7}$ Franklin Mariño-Sánchez,, ${ }^{1,7}$ Llorenç Quintó,,${ }^{3,8}$ \\ Josep de Haro, ${ }^{4}$ Manuel Bernal-Sprekelsen, ${ }^{1,7}$ Antonio Valero, ${ }^{5,7}$ Cèsar Picado, ${ }^{5,7}$ \\ Concepció Marin ${ }^{6,9}$
}

To cite: Mullol J, Alobid I, Mariño-Sánchez $\mathrm{F}$, et al. Furthering the understanding of olfaction, prevalence of loss of smell and risk factors: a population-based survey (OLFACAT study). BMJ Open 2012;2: 001256.

doi:10.1136/bmjopen-2012001256

- Prepublication history for this paper are available online. To view these files please visit the journal online (http://dx.doi.org/10.1136/ bmjopen-2012-001256).

Received 5 April 2012 Accepted 27 September 2012

This final article is available for use under the terms of the Creative Commons Attribution Non-Commercial 2.0 Licence; see http://bmjopen.bmj.com

For numbered affiliations see end of article

Correspondence to Dr Joaquim Mullol; jmullol@clinic.ub.es

\section{ABSTRACT}

Objectives: To investigate olfaction in general population, prevalence of olfactory dysfunction and related risk factors.

Design: Cross-sectional population-based survey, distributing four microencapsulated odorants (rose, banana, musk and gas) and two self-administered questionnaires (odour description; epidemiology/health status).

Setting: The survey was distributed to general population through a bilingual (Catalan, Spanish) newspaper in Catalonia (Spain), on December 2003.

Participants: Newspaper readers of all ages and gender; 9348 surveys were analysed from the 10783 returned.

Main outcome measures: Characteristics of surveyed population, olfaction by age and gender, smell self-perception and smell impairment risk factors. Terms normosmia, hyposmia and anosmia were used when participants detected, recognised or identified all four, one to three or none of the odours, respectively.

Results: Survey profile was a 43-year-old woman with medium-high educational level, living in a city. Olfaction was considered normal in $80.6 \%$ (detection), $56 \%$ (recognition/memory) and $50.7 \%$ (identification). Prevalence of smell dysfunction was $19.4 \%$ for detection ( $0.3 \%$ anosmia, $19.1 \%$ hyposmia), $43.5 \%$ for recognition ( $0.2 \%$ anosmia, $43.3 \%$ hyposmia) and $48.8 \%$ for identification $(0.8 \%$ anosmia, $48 \%$ hyposmia). Olfaction was worse $(p<0.0001)$ in men than in women through all ages. There was a significant age-related smell detection decline however smell recognition and identification increased up to fourth decade and declined after the sixth decade of life. Risk factors for anosmia were: male gender, loss of smell history and poor olfactory self-perception for detection; low educational level, poor self-perception and pregnancy for recognition; and older age, poor selfperception and history of head trauma and loss of smell for identification. Smoking and exposure to noxious substances were mild protective factors for smell recognition.

Conclusions: Sense of smell in women is better than in men suggesting a learning process during life with

\section{ARTICLE SUMMARY}

Article focus

- Population-based smell survey in 2003.

- Partial and total smell impairment by age and gender.

- Risk factors for olfactory disorders.

Key messages

- Olfaction is better in women than in men.

- Smell improves with a learning process and deteriorates in older ages.

- Poor olfactory self-perception, history of smell loss for over 1 week, head trauma and pregnancy are potential risk factors for olfactory disorders.

Strengths and limitations of this study

- The largest European population-based study providing data on partial/total loss of smell and their absolute risk factors.

- Self-administered survey (no control on how it was performed); the study was done in a middlehigh sociocultural population (newspaper readers).

deterioration in older ages. Poor self-perception, history of smell loss, head trauma and pregnancy are potential risk factors for olfactory disorders.

\section{INTRODUCTION}

The sense of smell provides information on the surrounding environment, warns us about chemical dangers and putrid food and may even help people to mate. Smell disorders may affect the ability to enjoy food and aromas while interfering with the ability to notice potentially harmful chemicals and gases. ${ }^{1}$

In 1987, the National Geographic Smell Survey (NGSS) studied a large US sample population (1.2 million) whereby $1 \%$ of 
participants could not smell three or more of six odorants using a 'scratch and sniff' test. ${ }^{2}$ Age was an important factor in smell deterioration and smell was rated better in women than in men. In 1994, the National Health Interview Survey ${ }^{3}$ reported data from 42000 USA households with $1.4 \%$ prevalence of self-reported olfactory dysfunction, exponentially increasing with age. This study, however, did not include any testing of smell function.

The prevalence and associated risk factors of olfactory impairment in the European population has been investigated to a limited extent. In the Swedish version of the NGSS, ${ }^{4}$ done in 532 individuals older than 45 years, increasing age was associated with impaired ability to detect/identify odorants, with no effect of gender on smell perception. Education has also been shown to account for a significant portion of the age-related variance in identification. ${ }^{5}$ Another European populationbased study identified a significant relationship between impaired olfaction and aging, male gender and nasal polyps, but not with diabetes or smoking, reporting an olfactory dysfunction prevalence of $19.1 \%{ }^{6}$

Approximately two-thirds of smell dysfunction cases are likely due to prior upper respiratory infections, head trauma or sinonasal diseases. ${ }^{7}$ Toxic chemical exposure, epilepsy, pollution, drugs, nutritional disturbances and neurodegenerative diseases may also cause olfactory disorders. ${ }^{8}$ Smoking may cause a reversible reduction in the ability to smell ${ }^{10}{ }^{11}$ while chronic rhinosinusitis/nasal polyps may result in a partial or total loss of smell. ${ }^{12}$

The aims of this study were to investigate the status of olfaction in the general population while determining the prevalence of olfactory dysfunction and its related risk factors.

\section{METHODS}

Study design

The OLFACAT (Olfaction in Catalonia) survey was carried out in the general population of Catalonia in Spain. Two questionnaires, olfaction and demographyhealth status and a set of four microencapsulated odorants were distributed in the 250000 daily issues of the newspaper El Periódico de Catalunya on 23 December 2003. The survey was presented in both Catalan and Spanish languages to facilitate the choice of the preferred language. The present manuscript has followed the STROBE checklist guidelines.

The study was approved by the Institutional Ethics and Clinical Research Committee of Hospital Clínic de Barcelona (reference 1295).

\section{Measurements}

Survey odorants

Four common odorants were included in the survey: rose (2\% of Bulgarian rose in $98 \%$ of phenyl-ethyl alcohol) as a floral odour; banana (amyl-isobutirate at $50 \%$ in dietyl-phtalate) as a food odour; musk (1:1 mixture of galaxolide and diethyl-phtalate exaltolide) as a perfume odour; and gas (mixture of 30\% mercaptan and $70 \%$ tetrahydrothiophene) as an industrial odour. Each compound was prepared following established formulas and the solution magnetically homogenised. Rose, banana and musk odorants were elaborated by Antonio Puig SA (Barcelona, Catalonia, Spain) and gas odorant by ENAGAS (Saragossa, Spain). Stability test protocols were performed by accelerating the olfactory aging of products at $40^{\circ} \mathrm{C}$ for 2 months, following their smell evolution after 1-8 weeks. The microencapsulation process was done by ARCADE Europe (Paris, France) as follows: essential oil component was contained and delivered from highly durable synthetic microcapsules manufactured using a proprietary polycondensated polymerisation method. The microcapsules were blended with a water-based polymer adhesive to form printable slurry. Odorants were adhered to a smell-less paper and dispatched using a folded-form design so as to prevent direct contact between odour samples.

\section{Smell questionnaire}

Participants were asked to scratch and sniff each odour and then answer three questions: first, odour detection: did you smell any scent? (yes, no); second, odour recognition/memory: have you ever smelt this scent? (yes, no) and third, forced-choice odour identification: which name defines the scent you have smelt?, whereby only one of the four given options was correct. The term 'normosmia' was used when a participant was able to detect, recognise (memory) or correctly identify all four tested odours; the term 'hyposmia' was used when a participant was not able to detect, recognise (memory) or correctly identify one, two or three tested odours and the term 'anosmia' was used when a participant was unable to detect, recognise (memory) or correctly identify any of the four tested odours.

\section{Epidemiological and health-status questionnaire}

From the 12-question questionnaire, four questions were on demography: first, gender (men and women); second, age (years); third, current educational level (primary school, secondary school, high school, University or College) and fourth, residential area (city and postcode). Two questions described smell selfperception: fifth, how do you consider your current sense of smell? (very good, good, poor and very poor) and sixth, have you ever lost the sense of smell? (never, up to 1 week and over 1 week). Two questions were on exposure to toxic or noxious substances: seventh, have you ever been exposed to dust, gases, fumes, vapours or/and volatile toxics at home and/or at work? (yes, no) and eighth, do you smoke? (no, exsmoker and smoker). Two questions were on health-status: ninth, have you ever had a severe face and/or head trauma? (yes, no) and 10th, have you ever been diagnosed with chronic rhinosinusitis? (yes, no). Finally, two questions were on women's 
health: 11th, are you currently pregnant? (yes, no); and 12 th, are you currently menstruating? (yes, no).

\section{Data management and statistical analysis}

The returned surveys were read using an optical system (BV Scan system, Voxpublica), the data were transferred to an electronic database, and then statistically analysed using Stata V.8 (Stata Statistical Software: Release 8.0 College Station, Texas, USA: Stata Corporation 2003). ${ }^{13}$ The data-cleaning process was based on programmed queries to identify records containing inconsistent or uncertain data. The corrupt or inaccurate values identified by these queries were subsequently recorded as missing values in the data set.

Only those surveys fully and consistently answered were considered for statistical analysis. Differences between gender in epidemiological and health-status characteristics were evaluated by $\chi^{2}$ test (table 4). Adjusted (multivariate) logistic regression models for anosmia and hyposmia were estimated (tables 1-3). To estimate the multivariate models for anosmia, the covariates that do not have any events (anosmia cases) in any of its categories were not included. Results from estimated models were expressed as adjusted OR and 95\% CI. The reference category used to calculate the OR for each level of variables measured on an ordinal scale was the immediately previous category, starting with the second. Results from estimated models were expressed as OR and 95\% CI. All tests were performed using a twotailed significance level of 0.05 .

\section{RESULTS}

\section{Characteristics of the surveyed population}

Following the data cleaning process, $5.6 \%$ of answers from the 10783 received surveys were identified as inconsistent. After the exclusion of both these inconsistent questionnaire returns and the incomplete epidemiological and health-status questionnaires $(7.7 \%)$, the sample size for analysis was 9348 questionnaires (figure 1).

\section{Age and gender}

The mean age of the surveyed population was 43.3 years, ranging from 5 to 91 years. The analysis was performed in seven age groups to ensure a reasonable sample size for each age and gender group. Almost two-thirds of participants were women $(65.7 \%)$, of which $2.1 \%$ were pregnant and $12.7 \%$ were menstruating (table 4 ).

\section{Education and residential zone}

Most participants $(83.8 \%)$ had a high educational level (high school or University/College) and were living $(93.9 \%)$ in an urban area, with no differences between genders (table 4).

\section{Exposure to tobacco and noxious substances}

More than one-fifth (21.4\%) of participants were smokers, $28.3 \%$ were exsmokers, while almost a third
$(29.9 \%)$ reported to be regularly exposed to toxic or noxious substances, either at home or at work. Men reported a higher exposure to both tobacco smoke $(24.8 \%, \mathrm{p}<0.0001)$ and noxious substances $(33.9 \%$, $\mathrm{p}<0.0001)$ than women $(19.7 \%$ and $27.7 \%$, respectively) (table 4).

\section{Health status}

In total, $4.4 \%$ of participants had received a diagnosis of chronic rhinosinusitis, with similar prevalence in women and men, while $5 \%$ reported a history of face/head trauma, this prevalence being higher in men than in women $(6.2 \%$ vs $4.3 \%, \mathrm{p}<0.0001)$ (table 4$)$.

\section{Sense of smell}

All four odours (normosmia) were detected by $80.6 \%$, recognised by $56 \%$, and identified by $50.7 \%$ of the surveyed population. One to three odours (hyposmia) were detected by $19.1 \%$, recognised by $43.3 \%$ and identified by $48 \%$. None of the four odours (anosmia) were detected by $0.3 \%$, recognised by $0.2 \%$ and identified by $0.8 \%$. Individual odours were more highly detected (rose $99.4 \%$, banana $98.9 \%$, gas $96.9 \%$ and musk $84.4 \%$ ) than recognised (rose $94.8 \%$, banana $96.2 \%$, gas $94.9 \%$ and musk $66.2 \%$ ) or correctly identified (rose $91.8 \%$, banana $89.8 \%$, gas $92.1 \%$ and musk $65.4 \%$ ). Moreover, individual odours were always better detected, recognised and identified by women than by men, except for rose and banana recognition.

\section{Smell by gender and age}

Within the population experiencing normosmia, there was a significant and progressive age-related decline of smell detection while smell recognition and identification increased up to the fourth decade of life, continued to plateau throughout the fifth and sixth decades, and declined thereafter. Significant but opposite findings were found for hyposmia and anosmia.

Normosmia was higher in women than in men $(\mathrm{p}<0.0001)$ either in smell detection $(82.8 \%$ vs $76.5 \%)$, recognition/memory $(58 \%$ vs $51.9 \%)$ or identification ( $54.1 \%$ vs $44.3 \%$; figure 2). Hyposmia was higher in men than in women $(\mathrm{p}<0.0001)$ either in smell detection $(22.8 \%$ vs $17.1 \%)$, recognition/memory $(47.1 \%$ vs $41.4 \%$ ) and identification (54\% vs $44.9 \%$; figure 3 ). Finally, anosmia was higher in men than in women in both smell detection $(0.9 \%$ vs $0.1 \% ; \mathrm{p}<0.0001)$ and identification $(1.2 \%$ vs $0.6 \%$; $\mathrm{p}=0.0057)$, but not in smell recognition/memory $(0.2 \%$ vs $0.2 \%, \mathrm{p}=0.9569$; figure 4$)$. In the oldest group (over 70 years), the prevalence for anosmia of detection (4.4\%) and identification (6.6\%) was especially higher in men than in women $(0 \%$ and $1.4 \%$, respectively; figure 4 ).

\section{Smell self-perception}

Subjective description of smell

Regardless of gender and age, $93.1 \%$ of participants subjectively rated their sense of smell as good or very good, 
Table 1 Distribution and relative risk for hyposmia (smell of one to three odours) or anosmia (smell of none of the four odours) in the case of smell detection using a multivariate logistic analysis of demographic and health problems

\begin{tabular}{|c|c|c|c|c|c|c|c|c|c|c|}
\hline \multirow[t]{3}{*}{ Covariable } & \multicolumn{5}{|c|}{ Hyposmia (detection) } & \multicolumn{5}{|c|}{ Anosmia (detection) } \\
\hline & \multicolumn{5}{|c|}{8601 Subjects, 1639 with hyposmia (19\%) } & \multicolumn{5}{|c|}{9251 Subjects, 25 with anosmia (0.3\%) } \\
\hline & No & Yes & Adjusted OR & $(95 \% \mathrm{Cl})$ & p Value & No & Yes & Adjusted OR & $(95 \% \mathrm{Cl})$ & p Value \\
\hline Female & $4686(67.3 \%)$ & $967(59.0 \%)$ & 0.78 & (0.69 to 0.88$)$ & $<0.0001$ & $6077(65.9 \%)$ & $7(28.0 \%)$ & 0.22 & $(0.07$ to 0.71$)$ & 0.0111 \\
\hline \multicolumn{11}{|l|}{ Educational level* } \\
\hline Elementary school & $23(0.3 \%)$ & $7(0.4 \%)$ & - & - & 0.0352 & $32(0.3 \%)$ & $0(0.0 \%)$ & - & - & - \\
\hline Middle school & $1061(15.2 \%)$ & $247(15.1 \%)$ & 0.76 & (0.32 to 1.81$)$ & & $1436(15.6 \%)$ & $8(32.0 \%)$ & - & - & \\
\hline High school & 3053 (43.9\%) & 683 (41.7\%) & 1.02 & (0.86 to 1.21$)$ & & 4020 (43.6\%) & $11(44.0 \%)$ & - & - & \\
\hline University & 2825 (40.6\%) & 702 (42.8\%) & 1.18 & (1.05 to 1.34 ) & & 3738 (40.5\%) & $6(24.0 \%)$ & - & - & \\
\hline \multicolumn{11}{|c|}{ Subjective description of sense of smell ${ }^{*}$} \\
\hline Very good & $1563(22.5 \%)$ & $275(16.8 \%)$ & - & - & $<0.0001$ & $1968(21.3 \%)$ & $2(8.0 \%)$ & - & - & $<0.0001$ \\
\hline Good & $4990(71.7 \%)$ & $1167(71.2 \%)$ & 1.24 & (1.08 to 1.44$)$ & & $6636(71.9 \%)$ & $2(8.0 \%)$ & 0.20 & (0.03 to 1.48$)$ & \\
\hline Poor & $388(5.6 \%)$ & $188(11.5 \%)$ & 1.94 & (1.58 to 2.37 ) & & $608(6.6 \%)$ & $5(20.0 \%)$ & 9.69 & (1.58 to 59.30$)$ & \\
\hline Very poor & $21(0.3 \%)$ & $9(0.5 \%)$ & 0.75 & (0.33 to 1.70$)$ & & $14(0.2 \%)$ & $16(64.0 \%)$ & 109.54 & (30.51 to 393.35 ) & \\
\hline \multicolumn{11}{|l|}{ Loss of smell history* } \\
\hline Never & $4829(69.4 \%)$ & $1130(68.9 \%)$ & - & - & 0.0935 & $6429(69.7 \%)$ & $5(20.0 \%)$ & - & - & 0.0172 \\
\hline$\leq 1$ week & $1796(25.8 \%)$ & 384 (23.4\%) & 0.88 & (0.78 to 1.01$)$ & & $2324(25.2 \%)$ & $1(4.0 \%)$ & 0.71 & (0.08 to 6.35$)$ & \\
\hline$>1$ week & 337 (4.8\%) & $125(7.6 \%)$ & 1.25 & (0.97 to 1.62$)$ & & $473(5.1 \%)$ & 19 (76.0\%) & 9.26 & (0.98 to 87.07$)$ & \\
\hline $\begin{array}{l}\text { Exposure to noxious } \\
\text { substances }\end{array}$ & $2023(29.1 \%)$ & $491(30.0 \%)$ & 1.02 & (0.91 to 1.16$)$ & 0.7025 & $2749(29.8 \%)$ & $9(36.0 \%)$ & 2.00 & (0.67 to 5.92$)$ & 0.2117 \\
\hline Chronic rhinosinusitis & $296(4.3 \%)$ & $75(4.6 \%)$ & 0.99 & (0.76 to 1.30$)$ & 0.9662 & 410 (4.4\%) & $3(12.0 \%)$ & 0.59 & (0.09 to 3.96$)$ & 0.5887 \\
\hline Menstruation & $616(8.8 \%)$ & $116(7.1 \%)$ & 0.97 & (0.78 to 1.20$)$ & 0.7655 & 777 (8.4\%) & $0(0.0 \%)$ & - & - & - \\
\hline \multicolumn{11}{|l|}{ Age $\left(\right.$ years) ${ }^{*}$} \\
\hline$<20$ & $374(5.4 \%)$ & $54(3.3 \%)$ & - & - & $<0.0001$ & $441(4.8 \%)$ & $1(4.0 \%)$ & - & - & - \\
\hline $20-29$ & $914(13.1 \%)$ & $163(9.9 \%)$ & 1.12 & (0.80 to 1.57$)$ & & $1118(12.1 \%)$ & $1(4.0 \%)$ & - & - & \\
\hline 30-39 & 1667 (23.9\%) & $356(21.7 \%)$ & 1.17 & (0.95 to 1.44$)$ & & $2150(23.3 \%)$ & $0(0.0 \%)$ & - & - & \\
\hline $40-49$ & 1893 (27.2\%) & $456(27.8 \%)$ & 1.14 & (0.97 to 1.33 ) & & $2514(27.2 \%)$ & $2(8.0 \%)$ & - & - & \\
\hline $50-59$ & $1360(19.5 \%)$ & $386(23.6 \%)$ & 1.17 & (1.00 to 1.37$)$ & & $1909(20.7 \%)$ & $7(28.0 \%)$ & - & - & \\
\hline $60-69$ & $528(7.6 \%)$ & $162(9.9 \%)$ & 1.08 & (0.88 to 1.34$)$ & & $779(8.4 \%)$ & $6(24.0 \%)$ & - & - & \\
\hline$>70$ & $226(3.2 \%)$ & $62(3.8 \%)$ & 0.85 & (0.61 to 1.19$)$ & & 315 (3.4\%) & $8(32.0 \%)$ & - & - & \\
\hline \multicolumn{11}{|l|}{ Residential zone† } \\
\hline Rural (reference) & $121(1.7 \%)$ & $31(1.9 \%)$ & 1 & - & 0.0821 & 165 (1.8\%) & $0(0.0 \%)$ & - & - & - \\
\hline Semirural & 294 (4.2\%) & $85(5.2 \%)$ & 1.15 & (0.72 to 1.83$)$ & & 403 (4.4\%) & $1(4.0 \%)$ & - & - & \\
\hline Urban & $6547(94.0 \%)$ & $1523(92.9 \%)$ & 0.87 & (0.58 to 1.30$)$ & & $8658(93.8 \%)$ & $24(96.0 \%)$ & - & - & \\
\hline \multicolumn{11}{|l|}{ Smoking† } \\
\hline $\begin{array}{l}\text { Non-smoker } \\
\text { (reference) }\end{array}$ & 3535 (50.8\%) & $789(48.1 \%)$ & 1 & - & 0.9331 & $4646(50.4 \%)$ & $10(40.0 \%)$ & 1 & - & 0.9608 \\
\hline
\end{tabular}




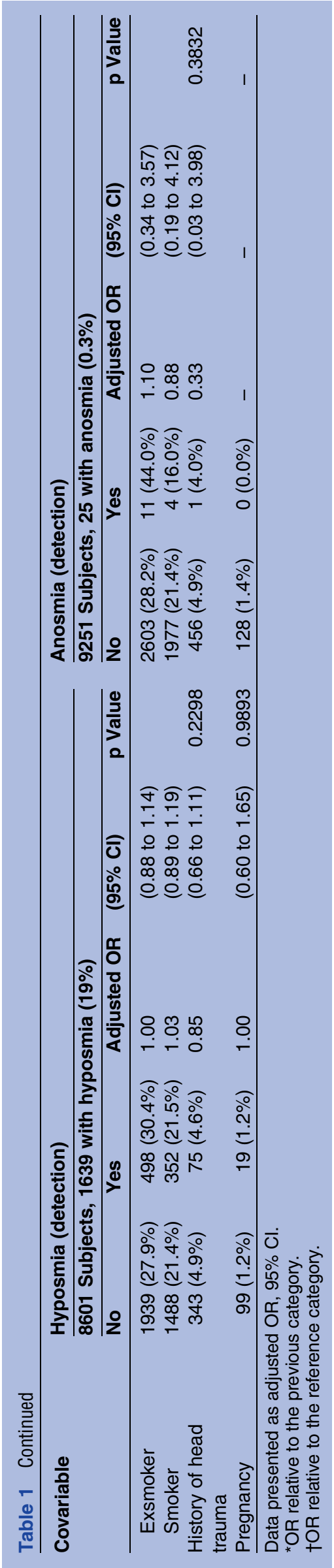

while $6.9 \%$ of them reported their smell as poor or very poor, the smell score being better in women than in men $(\mathrm{p}<0.0001)$ (table 4).

\section{Loss of smell history}

A history of loss of smell was reported by almost one-third $(30.4 \%)$ of participants, predominantly for less than 1 week $(25.1 \%)$. The smell loss for over 1 week was more frequent in men $(6.4 \%$ vs $4.8 \%, \mathrm{p}=0.0042)$ (table 4$)$.

\section{Risk factors for smell impairment}

Smell detection

Women detected odours more frequently than men ( $82.8 \%$ vs $76.5 \%, \mathrm{p}<0.0001)$. The risk for anosmia of detection was lower in women $(\mathrm{OR}=0.22)$ and higher in subjects reporting a loss of smell history for over 1 week $(\mathrm{OR}=9.26)$; and anosmia was also associated with a worse smell self-perception (table 1). The risk for hyposmia of detection was lower in women $(\mathrm{OR}=0.78)$ and associated with older age ( $>50$-year-old), a lower educational level and a worse smell self-perception (table 1).

\section{Smell recognition/memory}

Women showed a better capability to recognise odours than men $(58 \%$ vs 51.9\%; $\mathrm{p}<0.0001)$. The risk for anosmia of recognition was higher in pregnant women $(\mathrm{OR}=6.94)$ and associated with a lower educational level and a worse smell self-perception (table 2). The risk for hyposmia of recognition was lower in women $(\mathrm{OR}=0.79)$ and higher in subjects reporting a loss of smell history for over 1 week $(\mathrm{OR}=1.23)$; and it was associated with older age $(>70$ years old), a lower educational level, and a worse smell self-perception. Smoking (both exsmokers and smokers; $\mathrm{OR}=0.80$ and 0.68 , respectively) and frequent contact with noxious substances $(\mathrm{OR}=0.83)$ were found to have a mild but significant protective effect on odour recognition/memory (table 2).

\section{Forced-choice smell identification}

Women performed better than men on odour identification $(54.1 \%$ vs $44.3 \%, \mathrm{p}<0.0001)$. The risk for anosmia of identification was higher in subjects reporting a history of head trauma $(\mathrm{OR}=3.38)$ and a loss of smell for over 1 week $(\mathrm{OR}=2.79)$, and it was associated with older age ( $>60$ years old) and a worse smell self-perception (table 3). The risk for hyposmia of identification was lower in women $(\mathrm{OR}=0.76)$ and higher in subjects reporting a loss of smell history for over 1 week $(\mathrm{OR}=1.28)$, and it was associated with older age (>60-year-old), a lower educational level and a smell worse self-perception (table 3).

\section{DISCUSSION}

The most important findings of the OLFACAT survey were: first, the overall prevalence of olfactory dysfunction in the case of detection was $19.4 \%$, with a total loss of smell (anosmia) of $0.3 \%$. Despite this high prevalence of 


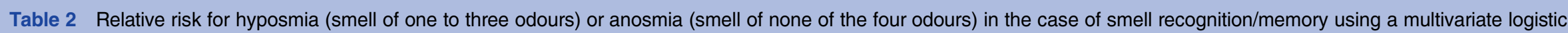
analysis of demographic characteristics and health problems

\begin{tabular}{|c|c|c|c|c|c|c|c|c|c|c|}
\hline \multirow[t]{3}{*}{ Covariable } & \multicolumn{5}{|c|}{ Hyposmia (recognition/memory) } & \multicolumn{5}{|c|}{ Anosmia (recognition/memory) } \\
\hline & \multicolumn{5}{|c|}{6778 Subjects, 2936 with hyposmia (43\%) } & \multicolumn{5}{|c|}{9079 Subjects, 18 with anosmia (0.2\%) } \\
\hline & No & Yes & Adjusted OR & $(95 \% \mathrm{Cl})$ & p Value & No & Yes & Adjusted OR & $(95 \% \mathrm{Cl})$ & p Value \\
\hline Female & $2663(69.3 \%)$ & $1885(64.2 \%)$ & 0.79 & (0.71 to 0.88$)$ & $<0.0001$ & $5986(66.1 \%)$ & $12(66.7 \%)$ & 1.26 & (0.41 to 3.81$)$ & 0.6879 \\
\hline \multicolumn{11}{|l|}{ Educational level ${ }^{*}$} \\
\hline Elementary school & $14(0.4 \%)$ & $14(0.5 \%)$ & - & - & 0.0200 & $31(0.3 \%)$ & $2(11.1 \%)$ & - & - & 0.0005 \\
\hline Middle school & $536(14.0 \%)$ & $505(17.2 \%)$ & 1.20 & (0.56 to 2.60$)$ & & $1387(15.3 \%)$ & $4(22.2 \%)$ & 0.05 & (0.01 to 0.29 ) & \\
\hline High school & $1671(43.5 \%)$ & $1272(43.3 \%)$ & 0.84 & (0.72 to 0.97$)$ & & $3942(43.5 \%)$ & $11(61.1 \%)$ & 1.18 & (0.34 to 4.08$)$ & \\
\hline University & $1621(42.2 \%)$ & 1145 (39.0\%) & 0.93 & (0.83 to 1.04$)$ & & 3701 (40.8\%) & $1(5.6 \%)$ & 0.09 & (0.01 to 0.73 ) & \\
\hline \multicolumn{11}{|c|}{ Subjective description of sense of smell ${ }^{*}$} \\
\hline Very good & $961(25.0 \%)$ & $532(18.1 \%)$ & - & - & $<0.0001$ & 1939 (21.4\%) & $3(16.7 \%)$ & - & - & 0.0039 \\
\hline Good & 2690 (70.0\%) & 2164 (73.7\%) & 1.45 & (1.28 to 1.64$)$ & & $6510(71.8 \%)$ & $12(66.7 \%)$ & 1.13 & (0.31 to 4.10$)$ & \\
\hline Poor & $187(4.9 \%)$ & $234(8.0 \%)$ & 1.62 & (1.30 to 2.01$)$ & & $600(6.6 \%)$ & $1(5.6 \%)$ & 0.75 & (0.08 to 7.40$)$ & \\
\hline Very poor & $4(0.1 \%)$ & $6(0.2 \%)$ & 0.98 & (0.26 to 3.66$)$ & & $12(0.1 \%)$ & $2(11.1 \%)$ & 65.35 & (4.60 to 927.55$)$ & \\
\hline \multicolumn{11}{|l|}{ Loss of smell history* } \\
\hline Never & 2620 (68.2\%) & $2087(71.1 \%)$ & - & - & 0.0020 & $6303(69.6 \%)$ & $11(61.1 \%)$ & - & - & 0.7159 \\
\hline$\leq 1$ week & $1050(27.3 \%)$ & $685(23.3 \%)$ & 0.81 & (0.73 to 0.91$)$ & & 2299 (25.4\%) & $4(22.2 \%)$ & 1.22 & (0.38 to 3.91$)$ & \\
\hline$>1$ week & $172(4.5 \%)$ & $164(5.6 \%)$ & 1.23 & (0.95 to 1.59$)$ & & $459(5.1 \%)$ & $3(16.7 \%)$ & 1.76 & (0.23 to 13.60$)$ & \\
\hline $\begin{array}{l}\text { Exposure to noxious } \\
\text { substances }\end{array}$ & $1201(31.3 \%)$ & $803(27.4 \%)$ & 0.83 & (0.74 to 0.93 ) & 0.0010 & $2694(29.7 \%)$ & $4(22.2 \%)$ & 0.58 & (0.18 to 1.82$)$ & 0.3497 \\
\hline Chronic rhinosinusitis & $168(4.4 \%)$ & $127(4.3 \%)$ & 1.02 & (0.80 to 1.30$)$ & 0.8574 & $404(4.5 \%)$ & $1(5.6 \%)$ & 0.72 & (0.08 to 6.40$)$ & 0.7720 \\
\hline Menstruation & $347(9.0 \%)$ & $249(8.5 \%)$ & 1.08 & (0.90 to 1.29$)$ & 0.4244 & $774(8.5 \%)$ & $1(5.6 \%)$ & 1.14 & (0.13 to 9.87$)$ & 0.9070 \\
\hline \multicolumn{11}{|l|}{ Age (years) ${ }^{*}$} \\
\hline$<20$ & $175(4.6 \%)$ & $214(7.3 \%)$ & - & - & $<0.0001$ & 437 (4.8\%) & $1(5.6 \%)$ & - & - & 0.7500 \\
\hline $20-29$ & $494(12.9 \%)$ & $405(13.8 \%)$ & 0.80 & (0.62 to 1.03$)$ & & $1108(12.2 \%)$ & $1(5.6 \%)$ & 1.06 & (0.06 to 18.62$)$ & \\
\hline $30-39$ & $956(24.9 \%)$ & $663(22.6 \%)$ & 0.81 & (0.68 to 0.96$)$ & & $2115(23.3 \%)$ & $4(22.2 \%)$ & 1.29 & (0.14 to 11.82$)$ & \\
\hline $40-49$ & $1088(28.3 \%)$ & $689(23.5 \%)$ & 0.91 & (0.79 to 1.04$)$ & & $2475(27.3 \%)$ & $2(11.1 \%)$ & 0.46 & $(0.08$ to 2.66$)$ & \\
\hline $50-59$ & $775(20.2 \%)$ & $564(19.2 \%)$ & 1.06 & (0.92 to 1.24$)$ & & $1881(20.8 \%)$ & $3(16.7 \%)$ & 1.74 & (0.28 to 10.81$)$ & \\
\hline $60-69$ & $268(7.0 \%)$ & $257(8.8 \%)$ & 1.22 & (0.99 to 1.50$)$ & & 755 (8.3\%) & $4(22.2 \%)$ & 1.84 & (0.37 to 9.12$)$ & \\
\hline$>70$ & $86(2.2 \%)$ & $144(4.9 \%)$ & 1.64 & (1.19 to 2.26$)$ & & $290(3.2 \%)$ & $3(16.7 \%)$ & 1.73 & (0.35 to 8.63$)$ & \\
\hline \multicolumn{11}{|l|}{ Residential zone† } \\
\hline Rural (reference) & $73(1.9 \%)$ & $49(1.7 \%)$ & 1 & - & 0.4187 & $164(1.8 \%)$ & $0(0.0 \%)$ & - & - & - \\
\hline Semi-rural & 157 (4.1\%) & $139(4.7 \%)$ & 1.27 & (0.82 to 1.96$)$ & & $390(4.3 \%)$ & $2(11.1 \%)$ & - & - & \\
\hline Urban & $3612(94.0 \%)$ & $2748(93.6 \%)$ & 1.10 & (0.76 to 1.59$)$ & & 8507 (93.9\%) & $16(88.9 \%)$ & - & - & \\
\hline \multicolumn{11}{|l|}{ Smokingt } \\
\hline $\begin{array}{l}\text { Non-smoker } \\
\text { (reference) }\end{array}$ & 1857 (48.3\%) & $1648(56.1 \%)$ & 1 & - & $<0.0001$ & 4567 (50.4\%) & $12(66.7 \%)$ & - & - & - \\
\hline Exsmoker & $1081(28.1 \%)$ & $766(26.1 \%)$ & 0.80 & (0.71 to 0.91$)$ & & 2537 (28.0\%) & $6(33.3 \%)$ & - & - & \\
\hline Smoker & 904 (23.5\%) & $522(17.8 \%)$ & 0.68 & (0.60 to 0.78$)$ & & 1957 (21.6\%) & $0(0.0 \%)$ & - & - & \\
\hline $\begin{array}{l}\text { History of head } \\
\text { trauma }\end{array}$ & $201(5.2 \%)$ & $134(4.6 \%)$ & 0.86 & (0.68 to 1.08$)$ & 0.1917 & 446 (4.9\%) & $0(0.0 \%)$ & - & - & - \\
\hline Pregnancy & $60(1.6 \%)$ & $35(1.2 \%)$ & 0.84 & (0.55 to 1.29$)$ & 0.4243 & $125(1.4 \%)$ & $1(5.6 \%)$ & 6.94 & (0.74 to 65.52$)$ & 0.0907 \\
\hline
\end{tabular}




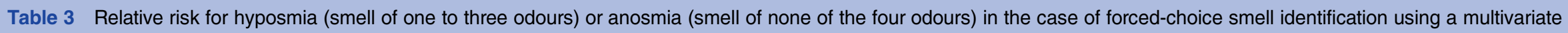
logistic analysis of demographic characteristics and health problems

\begin{tabular}{|c|c|c|c|c|c|c|c|c|c|c|}
\hline \multirow{3}{*}{ Covariable } & \multicolumn{5}{|c|}{ Hyposmia (identification) } & \multicolumn{5}{|c|}{ Anosmia (identification) } \\
\hline & \multicolumn{5}{|c|}{8107 Subjects, 3894 with hyposmia (48\%) } & \multicolumn{5}{|c|}{9195 Subjects, 75 with anosmia (1\%) } \\
\hline & No & Yes & Adjusted OR & $(95 \% \mathrm{Cl})$ & p Value & No & Yes & Adjusted OR & $(95 \% \mathrm{Cl})$ & p Value \\
\hline Female & $2911(69.1 \%)$ & $2368(60.8 \%)$ & 0.76 & (0.69 to 0.84$)$ & $<0.0001$ & $6008(65.9 \%)$ & $38(50.7 \%)$ & 0.96 & (0.55 to 1.67$)$ & 0.8850 \\
\hline \multicolumn{11}{|l|}{ Educational level* } \\
\hline Elementary school & $8(0.2 \%)$ & $18(0.5 \%)$ & - & - & 0.0007 & $31(0.3 \%)$ & $0(0.0 \%)$ & - & - & - \\
\hline Middle school & $654(15.5 \%)$ & $608(15.6 \%)$ & 0.49 & (0.21 to 1.16$)$ & & $1419(15.6 \%)$ & $24(32.0 \%)$ & - & - & \\
\hline High school & $1881(44.6 \%)$ & $1636(42.0 \%)$ & 1.01 & (0.88 to 1.15$)$ & & $3970(43.5 \%)$ & $28(37.3 \%)$ & - & - & \\
\hline University & $1670(39.6 \%)$ & $1632(41.9 \%)$ & 1.21 & (1.09 to 1.34$)$ & & 3700 (40.6\%) & $23(30.7 \%)$ & - & - & \\
\hline \multicolumn{11}{|c|}{ Subjective description of sense of smell ${ }^{*}$} \\
\hline Very good & $1034(24.5 \%)$ & $667(17.1 \%)$ & - & - & $<0.0001$ & 1948 (21.4\%) & $8(10.7 \%)$ & - & - & $<0.0001$ \\
\hline Good & $2979(70.7 \%)$ & $2841(73.0 \%)$ & 1.42 & (1.27 to 1.58$)$ & & 6567 (72.0\%) & $38(50.7 \%)$ & 1.27 & (0.59 to 2.76$)$ & \\
\hline Poor & $183(4.3 \%)$ & $374(9.6 \%)$ & 2.06 & (1.69 to 2.51$)$ & & $592(6.5 \%)$ & $13(17.3 \%)$ & 2.16 & (1.00 to 4.66$)$ & \\
\hline Very poor & $17(0.4 \%)$ & $12(0.3 \%)$ & 0.26 & (0.12 to 0.56$)$ & & $13(0.1 \%)$ & $16(21.3 \%)$ & 36.06 & (13.12 to 99.13$)$ & \\
\hline \multicolumn{11}{|l|}{ Loss of smell history* } \\
\hline Never & 2895 (68.7\%) & $2741(70.4 \%)$ & - & - & 0.0005 & $6361(69.7 \%)$ & $38(50.7 \%)$ & - & - & 0.0415 \\
\hline$\leq 1$ week & $1130(26.8 \%)$ & $901(23.1 \%)$ & 0.82 & (0.74 to 0.91$)$ & & $2301(25.2 \%)$ & $12(16.0 \%)$ & 0.93 & (0.48 to 1.81$)$ & \\
\hline$>1$ week & $188(4.5 \%)$ & $252(6.5 \%)$ & 1.28 & (1.02 to 1.62$)$ & & $458(5.0 \%)$ & 25 (33.3\%) & 2.79 & (1.14 to 6.88$)$ & \\
\hline $\begin{array}{l}\text { Exposure to noxious } \\
\text { substances }\end{array}$ & $1255(29.8 \%)$ & $1132(29.1 \%)$ & 0.98 & (0.89 to 1.08 ) & 0.6930 & $2716(29.8 \%)$ & $23(30.7 \%)$ & 1.03 & (0.60 to 1.77 ) & 0.9111 \\
\hline Chronic rhinosinusitis & $187(4.4 \%)$ & $170(4.4 \%)$ & 0.96 & (0.77 to 1.20$)$ & 0.7290 & $403(4.4 \%)$ & $5(6.7 \%)$ & 0.80 & (0.28 to 2.29$)$ & 0.6824 \\
\hline Menstruation & $390(9.3 \%)$ & $304(7.8 \%)$ & 1.03 & (0.87 to 1.22$)$ & 0.7157 & $772(8.5 \%)$ & $2(2.7 \%)$ & 0.49 & (0.11 to 2.14 ) & 0.3421 \\
\hline \multicolumn{11}{|l|}{ Age (years) ${ }^{*}$} \\
\hline$<20$ & 203 (4.8\%) & $194(5.0 \%)$ & - & - & $<0.0001$ & 438 (4.8\%) & $3(4.0 \%)$ & - & - & 0.0006 \\
\hline 20-29 & $551(13.1 \%)$ & $466(12.0 \%)$ & 0.82 & (0.64 to 1.04$)$ & & $1106(12.1 \%)$ & $8(10.7 \%)$ & 0.76 & (0.19 to 2.96$)$ & \\
\hline $30-39$ & $1032(24.5 \%)$ & $839(21.5 \%)$ & 0.94 & (0.80 to 1.10$)$ & & $2131(23.4 \%)$ & $11(14.7 \%)$ & 0.65 & (0.25 to 1.68$)$ & \\
\hline $40-49$ & $1198(28.4 \%)$ & $1004(25.8 \%)$ & 1.05 & (0.93 to 1.19 ) & & $2490(27.3 \%)$ & $10(13.3 \%)$ & 0.68 & (0.28 to 1.65$)$ & \\
\hline $50-59$ & $822(19.5 \%)$ & $831(21.3 \%)$ & 1.20 & (1.05 to 1.37$)$ & & $1886(20.7 \%)$ & $12(16.0 \%)$ & 1.40 & (0.58 to 3.38$)$ & \\
\hline $60-69$ & $302(7.2 \%)$ & $371(9.5 \%)$ & 1.19 & (0.99 to 1.43 ) & & $763(8.4 \%)$ & $17(22.7 \%)$ & 3.38 & (1.51 to 7.55 ) & \\
\hline$>70$ & $105(2.5 \%)$ & $189(4.9 \%)$ & 1.43 & (1.07 to 1.91$)$ & & $306(3.4 \%)$ & $14(18.7 \%)$ & 1.24 & (0.51 to 3.01 ) & \\
\hline \multicolumn{11}{|l|}{ Residential zone† } \\
\hline Rural (reference) & $76(1.8 \%)$ & $71(1.8 \%)$ & 1 & - & 0.3585 & $162(1.8 \%)$ & $1(1.3 \%)$ & 1 & - & 0.9858 \\
\hline Semi-rural & $176(4.2 \%)$ & $181(4.6 \%)$ & 1.11 & (0.75 to 1.65$)$ & & $400(4.4 \%)$ & $3(4.0 \%)$ & 0.87 & (0.08 to 8.95$)$ & \\
\hline Urban & $3961(94.0 \%)$ & 3642 (93.5\%) & 0.95 & (0.68 to 1.33 ) & & $8558(93.8 \%)$ & $71(94.7 \%)$ & 0.85 & (0.12 to 6.21$)$ & \\
\hline \multicolumn{11}{|l|}{ Smoking } \\
\hline $\begin{array}{l}\text { Non-smoker } \\
\text { (reference) }\end{array}$ & $2118(50.3 \%)$ & 1968 (50.5\%) & 1 & - & 0.5326 & 4594 (50.4\%) & $30(40.0 \%)$ & 1 & - & 0.2814 \\
\hline Exsmoker & 1169 (27.7\%) & $1131(29.0 \%)$ & 0.96 & (0.86 to 1.07$)$ & & 2567 (28.1\%) & $30(40.0 \%)$ & 1.61 & (0.88 to 2.93 ) & \\
\hline Smoker & $926(22.0 \%)$ & 795 (20.4\%) & 0.94 & (0.83 to 1.06$)$ & & 1959 (21.5\%) & $15(20.0 \%)$ & 1.41 & (0.70 to 2.82 ) & \\
\hline $\begin{array}{l}\text { History of head } \\
\text { trauma }\end{array}$ & $204(4.8 \%)$ & $193(5.0 \%)$ & 0.97 & (0.79 to 1.20$)$ & 0.7963 & $442(4.8 \%)$ & $12(16.0 \%)$ & 3.38 & (1.69 to 6.74 ) & 0.0006 \\
\hline Pregnancy & $62(1.5 \%)$ & $48(1.2 \%)$ & 1.02 & (0.69 to 1.51$)$ & 0.9157 & $126(1.4 \%)$ & $1(1.3 \%)$ & 1.72 & (0.22 to 13.33$)$ & 0.6017 \\
\hline
\end{tabular}




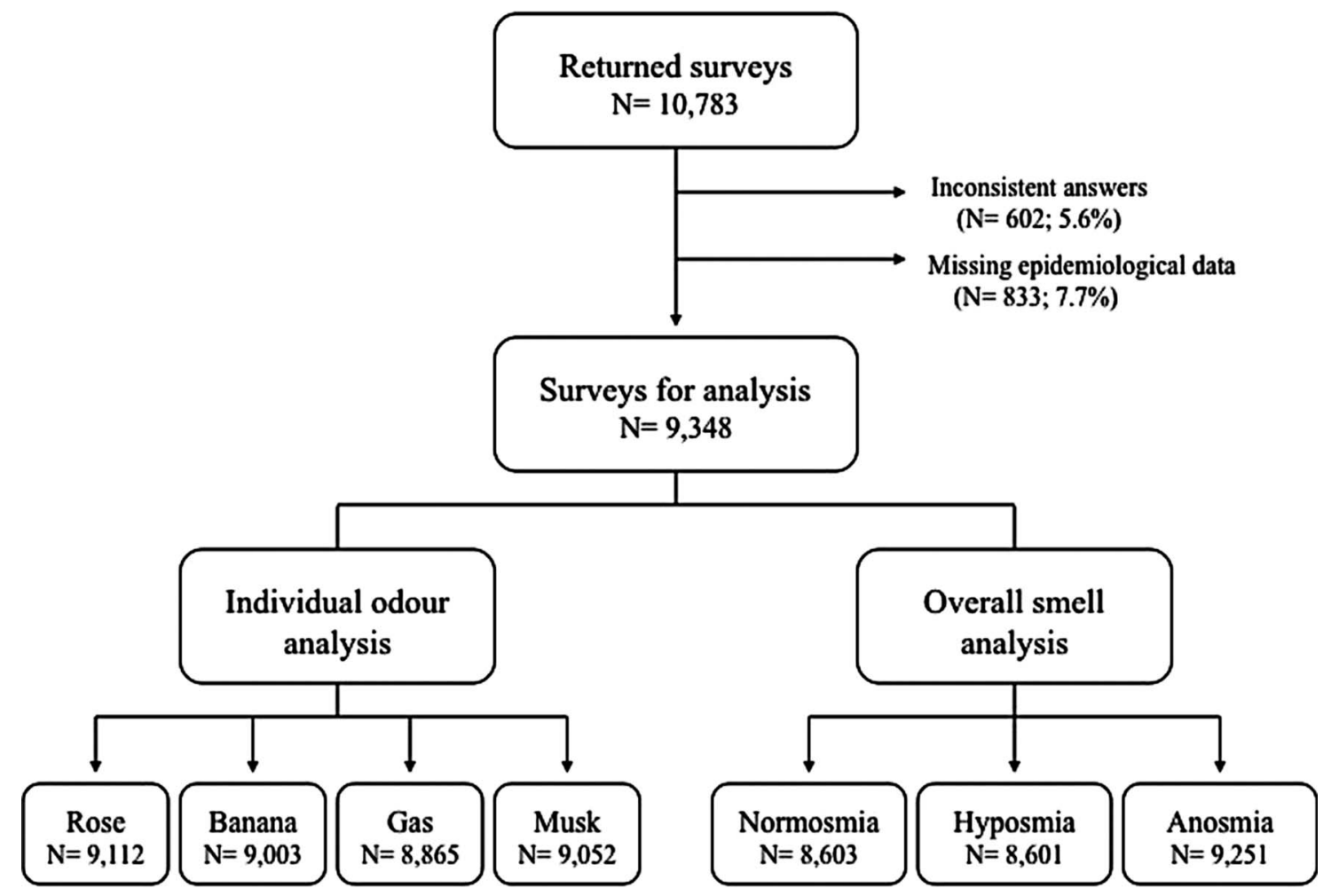

Figure 1 Flow-chart of participants in the OLFACAT (Olfaction in Catalonia) survey.

smell impairment, only $6.9 \%$ of the subjects considered having a poor or very poor sense of smell. Second, there was a significant age-related decline in smell detection for both genders. However, cognitive smell (recognition and identification) was increased and/or was maintained up to the sixth decade of life, declining thereafter. Third, besides women having a better self-perception of smell capabilities than men, women also scored better than men in smell detection, recognition and identification, and did so throughout their lifetime. Fourth, pregnancy, but not menstruation was associated with a partial loss (hyposmia) of smell recognition. Fifth, male gender, poor smell self-perception, low educational level and ageing, but not chronic rhinosinusitis, were risk factors related to smell impairment whether in terms of detection, recognition or identification. Subjects with a history of persistent olfactory loss or head trauma were also at higher risk of smell impairment. Sixth, finally and surprisingly, persistent exposure to noxious substances and smoking showed to be protective factors for cognitive smell impairment in either recognition or identification.

Approximately 6.4 million Catalans, 39.5 million Spaniards and 425 million European Union (EU) citizens are aged 15 years or older, according to Catalan, Spanish and European Statistic Institutes. Our survey therefore estimates that 1.2 million adult Catalans, 7.7 million Spaniards and over 82 million EU citizens suffering from olfactory dysfunction, of which 20000 Catalans, 120000 Spaniards and 1.5 million EU citizens have a total loss of sense of smell.
Brämerson et $a l^{6}$ reported an overall prevalence of olfactory impairment of $19.1 \%$ in a Swedish population which was very similar to our $19.4 \%$. This prevalence is considerably higher than self-reported loss of smell in the $\operatorname{NGSS}^{2}(1.4 \%)$ and in our own survey where $6.9 \%$ of participants were considered to have a poor or very poor sense of smell, suggesting a low sensitivity for the subjective assessment of smell loss. The fact that many people may be unaware of their smell dysfunction, especially the elderly and/or those living alone, implies an increased risk for both nutritional problems ${ }^{14}$ and safety in the face of a potential domestic fire or gas leak. ${ }^{15}$

In accordance with the OLFACAT survey data, previous studies have indicated that sense of smell detection is impaired with ageing, even in healthy individuals ${ }^{16}$ and from the second to the eighth decade of life. ${ }^{17}$ Our data also align with the NGSS and other studies in that the age decline in odour perception is universal across subjects regardless of gender odorants, outcome measures, or cultural diversity. ${ }^{2}{ }^{6}$ Smell changes observed across the survey's age span are similar to a previous study reporting a progressive decline in odour. ${ }^{18}$ Concerning cognitive smell (memory and identification), we observed an increase in performance in the first decades of life, reaching a plateau during the third through to fifth decades of life and declining thereafter. Larsson et at $t^{4}$ reported that age was associated with an increased ability to identify banana odour (amylacetate). Our survey, in agreement with the NGSS findings, found not only an increased ability to recognise and identify 
Table 4 OLFACAT (Olfaction in Catalonia) epidemiological characteristics and gender comparison: age, women's health, education level, smoking and toxic exposure, subjective description of smell, residential zone, history of head trauma, chronic rhinosinusitis and loss of smell history

\begin{tabular}{|c|c|c|c|c|}
\hline & Male, N (\%) & Female, N (\%) & Total, N (\%) & p Value \\
\hline Population characteristics ${ }^{*}$ & $3211(34.3)$ & $6137(65.7)$ & $9348(100)$ & \\
\hline \multicolumn{5}{|l|}{ Age (years)* ${ }^{\star}$} \\
\hline$<20$ & 127 (3.9) & $315(5.1)$ & $442(4.7)$ & \multirow[t]{7}{*}{$<0.0001 \dagger$} \\
\hline $20-29$ & $241(7.5)$ & $878(14.3)$ & 1119 (12.0) & \\
\hline $30-39$ & $668(20.8)$ & $1487(24.2)$ & $2155(23.1)$ & \\
\hline $40-49$ & $861(26.8)$ & $1673(27.3)$ & $2534(27.1)$ & \\
\hline $50-59$ & 766 (23.9) & $1181(19.3)$ & $1947(20.8)$ & \\
\hline $60-69$ & $355(11.1)$ & $454(7.4)$ & $809(8.6)$ & \\
\hline$>70$ & $193(6.0)$ & $149(2.4)$ & $342(3.7)$ & \\
\hline Menstruation* ${ }^{*}$ & & $781(12.7)$ & & \\
\hline Pregnancy* & & $128(2.1)$ & & \\
\hline \multicolumn{5}{|l|}{ Educational level ${ }^{\star}$} \\
\hline Elementary school & $7(0.2)$ & $26(0.4)$ & $33(0.3)$ & \multirow[t]{4}{*}{$<0.0001 \dagger$} \\
\hline Secondary school & $508(15.8)$ & 978 (15.9) & $1486(15.9)$ & \\
\hline High school & 1505 (46.9) & 2568 (41.9) & 4073 (43.6) & \\
\hline University/college & $1191(37.1)$ & 2565 (41.8) & 3756 (40.2) & \\
\hline \multicolumn{5}{|l|}{ Smoking* } \\
\hline Non-smokers & 1185 (36.9) & $3513(57.2)$ & $4698(50.3)$ & \multirow[t]{3}{*}{$<0.0001 \dagger$} \\
\hline Ex-smokers & $1231(38.3)$ & $1418(23.1)$ & 2649 (28.3) & \\
\hline Smoker & $795(24.8)$ & 1206 (19.7) & $2001(21.4)$ & \\
\hline \multicolumn{5}{|c|}{ Subjective description of sense of smell ${ }^{\star}$} \\
\hline Very good & 407 (12.7) & $1576(25.7)$ & $1983(21.2)$ & \multirow[t]{4}{*}{$<0.0001 \dagger$} \\
\hline Good & $2472(77.0)$ & $4243(69.1)$ & 6715 (71.9) & \\
\hline Poor & $315(9.8)$ & $305(5.0)$ & $620(6.6)$ & \\
\hline Very poor & $17(0.5)$ & $13(0.2)$ & $30(0.3)$ & \\
\hline \multicolumn{5}{|l|}{ Residential zone* } \\
\hline Rural & $57(1.8)$ & $109(1.8)$ & $166(1.8)$ & \multirow[t]{3}{*}{$0.9535 \dagger$} \\
\hline Semirural & $142(4.4)$ & $263(4.3)$ & $405(4.3)$ & \\
\hline Urban & 3012 (93.8) & 5765 (93.9) & 8777 (93.9) & \\
\hline History of head trauma* & $200(6.2)$ & $264(4.3)$ & $464(5.0)$ & $<0.0001 \dagger$ \\
\hline Exposure to noxious substances ${ }^{*}$ & 1090 (33.9) & $1703(27.7)$ & 2793 (29.9) & $<0.0001 \dagger$ \\
\hline Chronic rhinosinusitis* & $137(4.3)$ & $277(4.5)$ & $414(4.4)$ & $0.5814 \dagger$ \\
\hline \multicolumn{5}{|l|}{ Loss of smell history ${ }^{\star}$} \\
\hline Never & $2217(69.0)$ & 4289 (69.9) & $6506(69.6)$ & \multirow[t]{3}{*}{$0.0042 \dagger$} \\
\hline$\leq 1$ week & 789 (24.6) & $1555(25.3)$ & $2344(25.1)$ & \\
\hline$>1$ week & $205(6.4)$ & $293(4.8)$ & $498(5.3)$ & \\
\hline
\end{tabular}

banana, but rose and gas also, with increase indicated up to the fifth decade of life but decreasing thereafter. Due to the fact that repeated exposure to odorants and olfactory training may increase olfactory identification skills without modifying odour detection, ${ }^{18}$ these age-increased abilities for smell identification but not for detection, could be explained by the acquisition of cognitive smell skills through learnt experience.

Among the potential mechanisms proposed for age-related olfactory loss are the replacement of olfactory mucosa with respiratory epithelium caused by disease or pollutant exposure, ${ }^{19}$ cribiform plate calcification, ${ }^{20}$ olfactory bulb atrophy, ${ }^{21}$ decreased number of glomeruli/mitral cells in the olfactory tract ${ }^{22}$ and/or volume loss in temporal lobe areas. ${ }^{23}$
In accordance with other studies, ${ }^{2}{ }^{6} 8$ our survey found that women performed better in olfactory tasks compared with men of the same age group as well as self-reporting a better perception of smell sense. This gender difference was maintained across the lifespan, and increased considerably after the seventh decade of life. However, other studies have not found gender differences in olfactory sensitivity and identification, although women were slightly better. ${ }^{4}$ We have to note that the rates of correctly identified odours $(54.1 \%$ by women, $44.3 \%$ by men) are lower than those found in the Barcelona Smell Test (BAST)-24 validation, ${ }^{24}$ in which the present survey is based, and a potential explanation could be that the OLFACAT study was done in the general population, with both healthy and 
NORMOSMIA

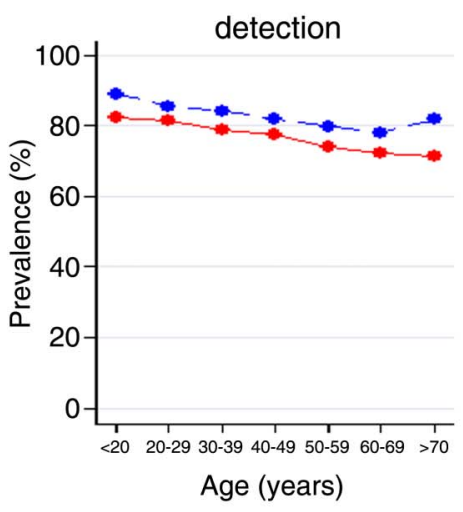

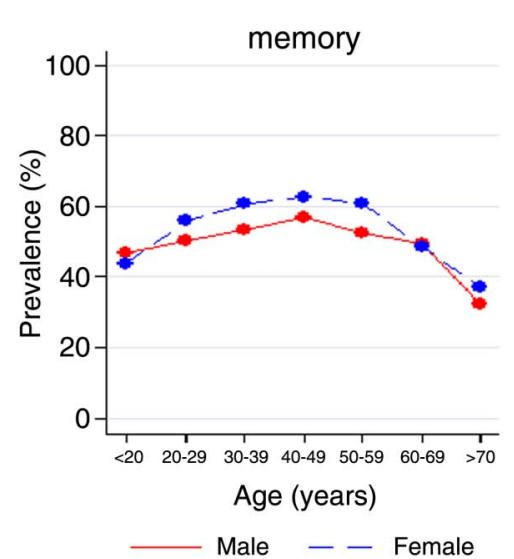

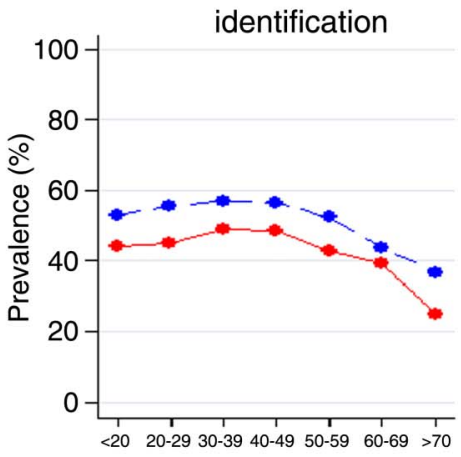

Age (years)

Figure 2 Evolution of normosmia (smell of all four odours) during lifetime. Smell detection showed a progressive decrease during the lifespan, while smell recognition/memory and identification increased up to the fourth decade of life, continued to plateau throughout the fifth and sixth decades, and declined thereafter. For detection, recognition/memory or identification, normosmia was significantly higher $(p<0.0001)$ in women (blue line) than in men (red line).

diseased participants, when in the BAST-24 validation all participants were healthy.

Interestingly, our survey found than pregnancy but not menstruation was associated with a lack of odour recognition/memory. Changes in odour perception during pregnancy have been investigated in small studies and with controversial findings, ${ }^{25}$ with olfactory dysfunction being more linked to changes in nasal sensitivity than in real smell perception. ${ }^{26}$ Clearly but not significantly, our survey showed that women had an increased risk for anosmia of smell recognition/memory during pregnancy $(\mathrm{n}=125, \mathrm{OR}=6.94)$.

In addition to male gender and ageing, we found that a history of transient olfactory loss for more than 1 week was associated to impairment in odour detection, recognition and identification. Postviral olfactory dysfunction has been found among the common causes of olfactory disorders of which spontaneous recovery might occur

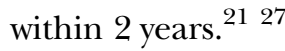

Moreover, survey participants with a history of head trauma had a higher risk of anosmia in the forcedchoice identification task. One of the major causes of smell dysfunction, affecting all ages, is traumatic brain injury, secondary to a partial or total damage of olfactory bulbs and tracts. This can involve frontal and temporal brain poles, as anosmia usually correlated with trauma severity. ${ }^{28}$

Although severe chronic rhinosinusitis with nasal polyps usually has a negative impact on smell function, ${ }^{12}$ our data did not identify chronic rhinosinusitis as being a risk factor for the loss of smell. This controversial finding, also described in other surveys, ${ }^{26}$ may be due

\section{HYPOSMIA}
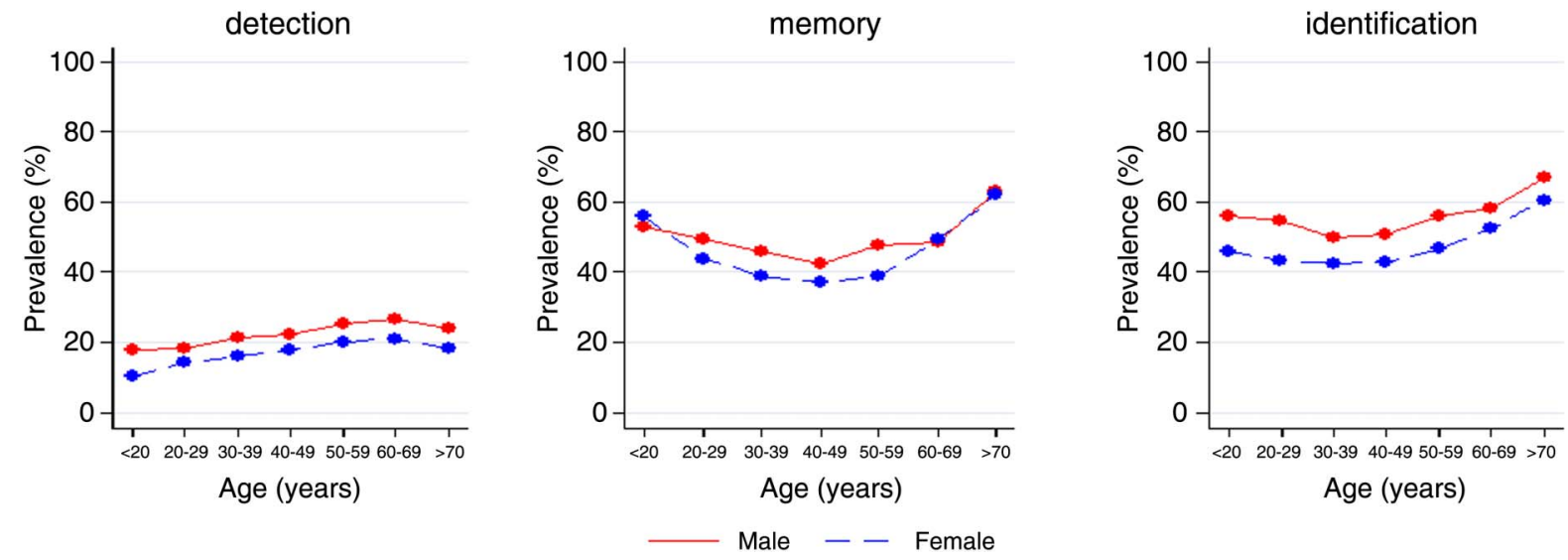

Figure 3 Evolution of hyposmia (smell of one to three odours) during lifetime. For detection, hyposmia showed a progressive increase during the life span, while for recognition/memory and identification hyposmia decreased up to the fourth decade of life, continued to plateau throughout the fifth and sixth decades and increased thereafter. For detection, recognition/memory or identification, hyposmia was significantly lower $(p<0.0001)$ in women (blue line) than in men (red line). 
ANOSMIA

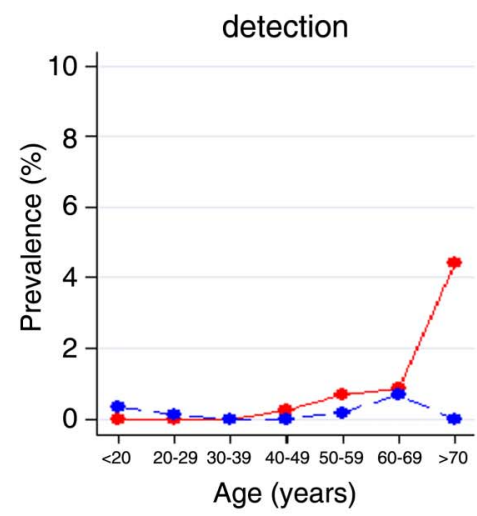

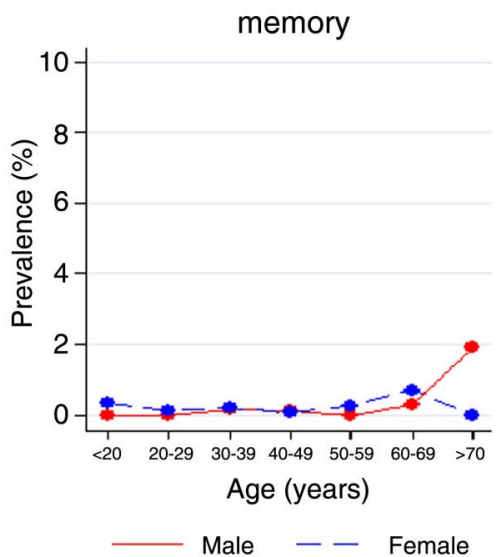

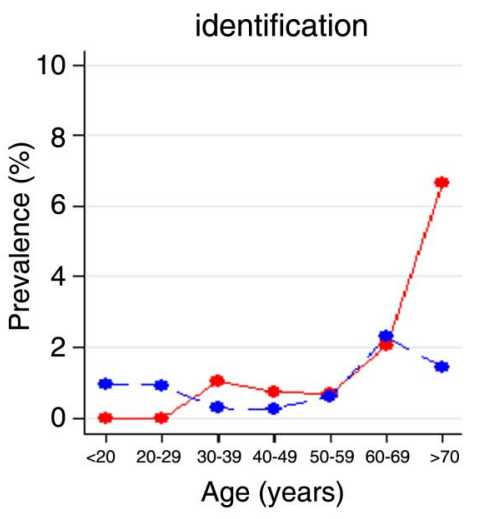

Age (years)

Figure 4 Evolution of anosmia (smell of none of the four odours) during lifetime. Anosmia showed a progressive mild increase during the life span but being more significant after the sixth decade of life. For detection, recognition/memory or identification, anosmia was significantly lower $(p<0.0001)$ in women (blue line) than in men (red line), with a maximal difference after the seventh decade of life.

either to possible mild levels of severity or selfmisdiagnosis of the disease among survey participants.

Studies on the impact of smoking on the sense of smell are not conclusive, specially when different smell qualities are considered. Some studies have shown adverse effects on smell detection, identification and intensity for some odours 81011 whereas others have found no effect on smell detection and discrimination for other odorants. ${ }^{9} 2629$ In our survey, data showed that smoking might be a mild but significant protective factor for cognitive smell. An explanation for this contradictory finding could be the activation of subtypeselective nicotinic receptors in the olfactory bulb. For instance, in neurodegenerative disorders such as Parkinson Disease (PD) olfactory loss is being considered as a significant early symptom that correlates with the progression of disease. ${ }^{30}$ In addition to the current evidence for the protective effect of smoking in PD, ${ }^{31}$ recent studies suggest that therapy with nicotine receptor agonists mediate enhancement of olfactory working memory in rats ${ }^{32}$ and could delay the progress of neurodegeneration in PD. ${ }^{33}$ However, further epidemiologic and mechanistic studies need to be done taking into account the different smell qualities (detection, memory and identification) to bring definitive light to the impact of smoking in the sense of smell.

Another interesting finding showed that odour performance was positively related to a level of education superior to primary school. It is known that odour identification and semantic memory proficiency tap the same domain, ${ }^{34}$ and that educational background is one of the most important predictors of cognitive decline with age, with cognitive deficits occurring earlier and more extensively in people with a low educational level. ${ }^{35}$ From an olfactory perspective, education and training may help to develop a wider repertoire of cognitive strategies to assist performance in verbal memory tasks, such as odour identification. $^{36}$

As with all epidemiological studies, the OLFACAT survey may have some weaknesses. (1) The survey population cannot be considered a random sample since there was no control over who and how the survey was performed or whether participants were preferentially motivated to answer the survey. (2) The survey's data may not be fully representative of the general population since the readership survey (2003) shows that the newspaper's readers belong to a higher socio-cultural class $(85.1 \%$ middle class) and have a higher educational level (31.1\% finished secondary school) than the general Catalan population $(65.0 \%$ and $25.6 \%$, respectively, 2002 census). (3) Although other studies have not found smell differences among different ethnic groups, the lack of ethnic diversity in our sample (mainly Caucasians) could limit the generalisation to other ethnic groups. (4) Cognitive disturbances in elderly individuals are characterised by impaired smell function but also potentially accounting for unwillingness to participate in the survey. (5) Subjects with smell impairment could have been more/less interested in participating in the survey leading to an over/underestimation of the prevalence of dysfunction. Observations were based on cross-sectional data, making it impossible to disentangle true ageing effects from cohort membership. (7) The survey could have a positive female response bias since almost two-thirds of participants who returned the surveys were women $(65.7 \%)$.

In agreement with earlier findings in other cultures, the present survey on the general population indicates an age-related deterioration in odour detection, recognition and identification, with a higher prevalence and a more manifest age decline in men than in women. Pregnancy, head trauma and a transient olfactory loss 
history are absolute risk factors for olfactory dysfunction while having a higher educational level and smoking may be protective factors for smell. In order to understand the role of smell in human behaviour and determine the potential influence of cognitive, sensorial and environmental factors, there is however an obvious need for well-designed longitudinal population-based studies, which deploy validated smell tests and consider the characteristics of the populations studied.

\section{Author affiliations}

${ }^{1}$ Unitat de Rinologia i Clínica de l'Olfacte, Servei d'Otorinolaringologia, Hospital Clínic i Universitari. Barcelona, Catalonia, Spain

${ }^{2}$ Immunoal.lèrgia Respiratòria Clínica i Experimental, Institut d'Investigacions Biomèdiques August Pi i Sunyer (IDIBAPS). Barcelona, Catalonia, Spain ${ }^{3}$ Centre de Recerca en Salut Internacional de Barcelona (CRESIB), Hospital Clínic i Universitari. Barcelona, Catalonia, Spain

${ }^{4}$ Servei d'Otorinolaringologia, Hospital Municipal de Badalona. Badalona, Catalonia, Spain

${ }^{5}$ Servei de Pneumologia i Al.lèrgia Respiratòria, ICT, Hospital Clínic i Universitari. Barcelona, Catalonia, Spain

${ }^{6}$ Laboratori de Neurologia Experimental, Institut d'Investigacions Biomèdiques August Pi i Sunyer (IDIBAPS). Barcelona, Catalonia, Spain

${ }^{7}$ Centro de Investigación Biomédica En Red en Enfermedades Respiratorias (CIBERES), Barcelona, Spain

${ }^{8}$ Centro de Investigación Biomédica En Red en Epidemiología y Salud Pública (CIBERESP)

${ }^{9}$ Centro de Investigación Biomédica En Red en Enfermedades Neurodegenerativas (CIBERNED)

Acknowledgements We thank for their technical assistance and support to the OLFACAT survey to: Rossend Mateu, Elizabeth Vidal, Albert Casacuberta, Carles M Pelejero, Montserrat Ribas, Elizabet Ribot, Josep Vivas and Montserrat Calzada from Antonio Puig SA; Nadine Jaouani and Philippe Ughetto from ARCADE Europe; Francesc Aldea from AstraZeneca; Josep Garcia-Miquel, Àngels Gallardo, Víctor Blanes, Joan C Brenchat, Augusto Bueno, Bernat Gasulla, Xavier Martínez-Chico and Antoni Pelegrin from El Periódico de Catalunya; JM López-Zurita from ENAGAS; Juan Solís, Sebastià Gumà and Maria C. González from Fundació Gas Natural; and Àngels Pont from VoxPublica/GESOP. Furthermore, we also thank for their collaboration in the OLFACAT survey to: Tomàs Molina from Televisió de Catalunya; Núria Cots, Sergi Paricio and Oriol Puig from Servei Meteorològic de Catalunya; Professor Jordina Belmonte from Universitat Autònoma de Barcelona; Professor Joan R Morante from Universitat de Barcelona and Professor Joan M Canals from Universitat Rovira i Virgili de Tarragona.

Contributors JM is the guarantor of the study, and has contributed with the conception and design of the study, literature search, acquisition of data, analysis and interpretation of data and writing the manuscript. IA and FM have contributed through literature research, interpretation of data and by drafting the manuscript; they approved the final version. LQ has contributed with the study design, acquisition of data, statistical analysis and interpretation of data and drafting the manuscript and approved the final version. JH has contributed with the conception and design of the study, acquisition and interpretation of data and a critical reading of the manuscript and approved the final version. $\mathrm{CP}, \mathrm{AV}$ and $\mathrm{MB}$ have contributed with the study design, interpretation of data, a critical reading of the manuscript and approved the final version. CM has contributed with the conception and design of the study, acquisition of data, analysis and interpretation of data and a critical reading of the manuscript; and approved the final version. All authors had full access to all of the data of the study including statistical reports and tables.

Funding This study was partially supported by Antonio Puig SA, Myrurgia, Fundació Gas Natural and ENAGAS for producing the odorants; ARCADE Europe for microencapsulating the odorants; El Periódico de Catalunya for printing, distributing, and collecting the surveys as well as for publishing a special issue on the sense of smell; AstraZeneca for supporting the investigator meetings; and Voxpublica (GESOP) for performed the survey optical reading and collecting the final data of the OLFACAT study. Some of the above study sponsors participated in the design of the survey (Antonio Puig, Fundació Gas Natural and ARCADE Europe) and in the collection of survey data (Voxpublica/GESOP). However, none of the sponsors participated in the analysis and interpretation of data, writing of the report and the decision to submit the report for publication.

\section{Competing interests None.}

Provenance and peer review Not commissioned; externally peer reviewed.

Data sharing statement No additional data are available.

\section{REFERENCES}

1. Santos DV, Reiter ER, DiNardo LJ, et al. Hazardous events associated with impaired olfactory function. Arch Otolaryngol Head Neck Surg 2004;130:317-19.

2. Wysocki CJ, Gilbert AN. National Geographic Smell Survey. Effects of age are heterogenous. Ann NY Acad Sci 1989;561:12-28.

3. Hoffman $\mathrm{HJ}$, Ishii EK, Macturk RH. Age-related changes in the prevalence of smell/taste problems among the United States adult population. Ann NY Acad Sci 1998;855:716-22.

4. Larsson M, Finkel D, Pedersen NL. Odor identification: influences of age, gender, cognition, and personality. J Gerontol B Psychol Sci Soc Sci 2000:55:304-10.

5. Larsson M, Nilsson L, Olofsson J, et al. Demographic and cognitive predictors of cued odor identification: evidence from a populationbased study. Chem Senses 2004;29:547-54.

6. Brämerson A, Johansson L, Ek L, et al. Prevalence of olfactory dysfunction: the skovde population-based study. Laryngoscope 2004;114:733-7.

7. Ciofalo A, Filiaci F, Romeo R, et al. Epidemiological aspects of olfactory dysfunction. Rhinology 2006;44:78-82

8. Murphy $\mathrm{C}$, Schubert CR, Cruickshanks KJ, et al. Prevalence of olfactory impairment in older adults. JAMA 2002;288:2307-12.

9. Landis BN, Konnerth CG, Hummel T. A study on the frequency of olfactory dysfunction. Laryngoscope 2004;114:1764-9.

10. Frye RE, Schwartz BS, Doty RL. Dose-related effects of cigarette smoking on olfactory function. JAMA 1990;263:1233-6.

11. Vennemann MM, Hummel T, Berger K. The association between smoking and smell and taste impairment in the general population. J Neurol 2008;255:1121-6.

12. Guilemany JM, Mariño-Sánchez FS, Angrill J, et al. The importance of smell in patients with bronchiectasis. Respir Med 2011;105:44-9.

13. Stata Statistical Software: Release 8.0. College Station, TX: Stata Corporation, 2003.

14. Davis L. Practical aspects of nutrition of the elderly at home. In: Munro H, Schlierf G, eds. Nutrition in the Elderly. Nestle Nutrition Workshop Series, vol. 29. New York, NY: Raven Press, 1992:203-9.

15. Chalke HD, Dewhurst JR. Accidental coal-gas poisoning. BMJ 1957;2:915-17.

16. Doty RL. Studies of human olfaction from the University of Pennsylvania Smell and Taste. Chem Senses 1997;22:565-86.

17. Doty RL, Shaman P, Applebaum SL, et al. Smell identification ability: changes with age. Science 1984;226:1441-3.

18. Mariño-Sánchez FS, Alobid I, Cantellas S, et al. Smell training increases cognitive smell skills of wine tasters compared to the general healthy population. The WINECAT Study. Rhinology 2010;48:273-6.

19. Nakashima T, Kimmelman CP, Snow IB. Structure of human fetal and adult olfactory neuroepithelium. Arch Otolaryngol 1984;110:641-6.

20. Krmpotic-Nemanic J. Presbycusis, presbystasis, and presbyosmia as consequences of the analagous biological process. Acta Otolaryngol 1969;67:217-23.

21. Rombaux P, Mouraux A, Bertrand B, et al. Olfactory function and olfactory bulb volume in patients with postinfectious olfactory loss. Laryngoscope 2006;116:436-9.

22. Meisami E, Mikhail L, Baim D, et al. Human Olfactory bulb: aging of glomeruli and mitral cells and a search for the accessory olfactory bulb. Ann NY Acad Sci 1998;855:708-15.

23. Jernigan TL, Archibald SL, Fennema-Notestine C, et al. Effects of age on tissues and regions of the cerebrum and cerebellum. Neurobiol Aging 2001;22:581-94. 
24. Cardesín A, Alobid I, Benítez P, et al. Barcelona Smell Test-24 (BAST-24): validation and smell characteristiques in the healthy Spanish population. Rhinology 2006;44:83-9.

25. Wohlgemuth $\mathrm{C}$, Beinder $\mathrm{E}$, Ochsenbein-Kölble N, et al. Changes in olfactory function with several pregnancies? Swiss Med Wkly 2008:138:466-9.

26. Nordin S, Broman DA, Olofsson JK, et al. A longitudinal descriptive study of self-reported abnormal smell and taste perception in pregnant women. Chem Senses 2004;29:391-402.

27. Welge-Lüssen $\mathrm{A}$, Wolfensberger $\mathrm{M}$. Olfactory disorders following upper respiratory tract infections. Adv Otorhinolaryngol 2006;63:125-32.

28. Sigurdardottir S, Jerstad T, Andelic N, et al. Olfactory dysfunction, gambling task performance and intracranial lesions after traumatic brain injury. Neuropsychology 2010;24:504-13.

29. Hubert HB, Fabsitz RR, Feinleib M, et al. Olfactory sensitivity in human: genetic versus environmental control. Science 1980;9:607-9.

30. Haehner A, Boesveldt S, Berendse HW, et al. Prevalence of smell loss in Parkinson's disease-a multicenter study. Parkinsonism Relat Disord 2009;15:490-4.
31. Wirdefeldt K, Adami HO, Cole P, et al. Epidemiology and etiology of Parkinson's disease: a review of the evidence. Eur J Epidemiol 2011;26(Suppl 1):S1-58.

32. Rushforth SL, Allison C, Wonnacott S, et al. Subtype-selective nicotinic agonists enhance olfactory working memory in normal rats: a novel use of the odour span task. Neurosci Lett 2010;471:114-18.

33. Shimohama S. Nicotinic receptor-mediated neuroprotection in neurodegenerative disease models. Biol Pharm Bull 2009;32:332-6.

34. Larsson M, Bäckman L. Age-related differences in episodic odour recognition: the role of access to specific odour names. Memory 1997;5:361-78.

35. Ardila A, Ostrosky-Solis F, Rosselli M, et al. Age-related cognitive decline during normal aging: the complex effect of education. Arch Clin Neuropsychol 2000;15:495-513.

36. Angel I, Fay S, Bouazzaoui B, et al. Protective role of educationa level on episodic memory aging: an event-related potential study. Brain Cognit 2010;74:312-23. 